\title{
Zwei Einzelbemerkungen.
}

\author{
I. Fes. 18,4 .
}

Der Vers bietet der Auslegung, wie ein Blick auf die älteren und neueren Kommentare zeigt, erhebliche Schwierigkeiten, sowohl sprachlich wie sachlich. Was der Prophet sagen will, ergiebt sich mit aller Deutlichkeit aus dem $\mathrm{Zu}$ sammenhang:

Jhvh hat sein Auge aufmerksam auf das Völkergetriebe gerichtet, aber wartet, bis seine Zeit da ist. Der Kontrast: Jhvh in seiner erhabenen Ruhe - die Völker in ihrem Drängen, muss die Pointe dessen sein, was im Bilde v. $4^{\mathrm{b}}$ beabsichtigt ist. ${ }^{\text {I }}$

Aber im Text, wie er vorliegt, kommt nur die eine Seite des Kontrastes (Jhvh's Ruhe) zum Ausdruck, die andre nicht.

$\mathrm{Zu}$ diesem sachlichen Anstoss gesellt sich der sprachliche.

Auffallend ist schon, dass in stilistisch unschöner (und verdächtiger) Weise an zweimal in einem Doppelzeiler vor-

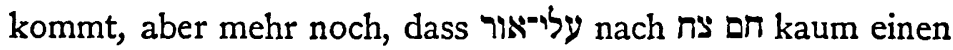
Sinn giebt. Wie wund die Stelle ist, zeigt Dillmann's Wiedergabe: „wie heitre Hitze bei (eig. auf Grund von) Sonnenschein". Es ist offenbar, dass er mit על עם

I Vgl besonders Marti Kom. z. d. St. Gesenius verweist treffend auf Ps. 2, 4 vgl. I. 
nichts Rechtes anzufangen gewusst hat. ${ }^{x}$ Duhm, der die ungezwungene Deutung von על עור beibehält, greift zu sachlichen Erklärungen, die wenig überzeugen. Das Flimmern in der Luft erscheint dem Auge wohl auch hoch oben am Himmel, aber niemals über der Sonne.

'Auf den richtigen Text scheint mir in diesem Fall ${ }^{2}$ die

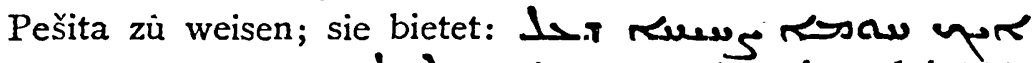
כחם d. צח על יאור כעב טל ביום קית תמיר

Die sprachlichen Schwierigkeiten sind hier verschwunden: ח kommt nur einmal vor und zwar in poetischem Gebrauch 3 als Synonym von שמש על מל aber bedarf keiner gezwungenen Deutung.

Der sachliche Vorzug aber ist evident:

Knapp und doch klar, wie es das göttliche Schlagwort sein muss, um in wirrer Zeit zu haften, bringen hier zwei analoge und doch reinlich geschiedene Bilder den erwarteten Kontrast in sprechender poetischer Schönheit:

I Vgl. Komm.5, S. I69. Bezeichnend ist auch, dass mehrere Rabbinen mit Verweisung auf Job 37, II I I I I I I Regen“ erklären, worauf sie sicherlich nicht verfallen wären, wenn der gewöhnliche Sinn nicht eine sehr unbequeme Häufung nach $\square$ ergäbe.

2 Ich verwende das Zeugnis der Peš. im vollen Bewusstsein ihrer Unzulänglichkeit für textkritische Zwecke. Im Buche Jesaia ist besonders deutlich, dass sie fast durchweg den masoretischen Text voraussetzt, und, wo sie abweicht, meist in ihrer Eigenschaft als Übersetzung abweicht. Wo sie einen glatteren und einfacheren Text als Ms. bietet, unterliegt sie dem Verdacht, sich über die vorhandenen Schwierigkeiten hinweggesetzt zu haben. Aber Schwierigkeiten, an denen die Peš. sich hätte stossen kōnnen, bietet unsre Stelle eben nicht. - Nicht zu übersehen ist, dass die LXX, denen die Peš. im Buche Jesaia sehr weitgehend zu folgen pflegt, hier aber nachweislich nicht gefolgt ist, mit $\eta \mu \varepsilon p \alpha 5$ gleichfalls or statt $ם$ voraussetzen.

3 Vgl. das verwandte חמן, wo es vorkommt: Job. 30, 28. Jes. 24, 23. 30, 26. Ct. 6, 10. (Ps. 19, 7) 
wie heitrer Sonnenschein über'm Strom, wie Thaugewölk am Erntetage.

Die Vorstellung eines Stromes ist untrennbar von der des unruhig hindrängenden und strudelnden Wassers, die Vorstellung eines Erntetages aber von der des Getümmels.

Es bedarf keines Hinweises, wie leise der Eingriff in den Text ist und wie leicht er sich in graphischer Hinsicht rechtfertigen lässt.

\section{Fes. $7,8.9$.}

Jhvh verheisst v. 7, was Rezin und der Sohn Remalja's gegen Juda planen, werde nicht geschehen. Das soll in v. 8.9 (vgl. ' ' ) begründet werden. Aber in der Hervorhebung der Thatsache, dass D. Haupt von A. ist u. s. w., ist schlechterdings kein Grund zu entdecken, es sei denn, dass hier prägnant geredet ist. Das nehmen auch die Kommentatoren notgedrungen an.

Und welches ist die Prägnanz?

Nach Gesenius (vgl. Dillmann): „Es ist und bleibt in Ansehung Ephraim's und Damaskus, in Ansehung des Pekah und Rezin, so, wie es ist: Die Gebiete jener Reiche werden nicht (durch Juda und Jerusalem) erweitert." s

Nach Hitzig, der diese Deutung verwirft, „verkleinert (der Prophet) die Macht der Feinde, indem er das je Stärkere dem Schwächeren überordnet, und das Stärkere doch noch als ohnmächtig vorführt: mächtig über Aram ist Damask, mächtig über Damask Rezin, und wer ist dieser Rezin? Der Stumpf eines ausgeglommenen Feuerbrandes.

I Das ist offenbar keine Begründung, sondern eine Bekräftigung von v. 7, gegen die sachlich einzuwenden ist, dass die beiden Reiche und Könige nach v. 16 eben nicht bleiben sollen, wie sie sind, sondern vernichtet werden. 
Es kommen zwei schwạche sterbliche Menschen gegen den Jehova daher".x

Nach Duhm: „Es sind Menschen und menschliche Mächte ......, ja es sind die wohlbekannten, vom Davididenhause zeitweilig beherrschten und von Assur nun Un'terjochten. ${ }^{2}$

Diese Beispiele mögen genügen um darzuthun, dass die Verlegenheit so gross ist, wie die Mannigfaltigkeit der Deutung. Es ist aber ungereimt, anzunehmen, der Prophet, der v. 7 mit kühnster und gewissester Weissagung hervorgetreten ist, habe sich zur Erklärung derselben in viel- bzw. nichtssagenden Orakelspruch gefüllt. So bliebe nur, sich zu bescheiden und hier eine den Zeitgenossen aus der Zeitlage deutliche, uns aber nicht mehr verständliche Anspielung anzuerkennen. Aber sollte die Lösung nicht in der doppelten Bedeutung von רהש liegen? Wenn D. als Hauptstadt zugleich das Gift(gewächs) von A., R. als Haupt zugleich das Gift(gewächs) von D. u. s. f. ist, begreift sich, warum die Anschläge $z u$ nichte werden müssen. Wo Gift ist, da ist nicht Blüte, sondern Verfall und Verderben.

Zum Gedanken, dass der Fürst sein Volk ins Verderben bringt, sc. durch Abenteuer und Kriegslust, vgl. Jud. 9, I 5. Pekah war durch Königsmord und Empörung auf den Thron gekommen, um, wie Rezin seinerseits auch, in verderblichen Gegensatz zu Assur zu treten. Rezin beschwor durch seine weitgehenden Eroberungen das Wetter geradezu auf sein Land herauf.

Dass aber in des Propheten Augen die Hauptstädte als

× Was Hitzig den Propheten sagen lässt, wird von ihm selbst als „Trugschluss"s abgethan. Vgl. den Komm. z. d. St.

2 Hier erscheinen 2 wei verschiedene Argumente nebeneinander, was die Unsicherheit deutlich zum Ausdruck bringt. Wie wenig sie stichbalten, erkennt Duhm selber an, indem er fortfährt: „Freilich sind sie Juda. überlegen .... 
Gift der dazugehörigen Länder gelten, kann nicht befremden, wenn man Schilderungen wie Jes. 28. Amos 6 u. a. vergleicht. Das Land ist, wie in die Schuld, so in das Schicksal der Hauptstadt verflochten (vgl. Jes. 1, 5).

Das Bild des unauffallig, aber unaufhaltsam wirkenden Giftes stimmt aufs beste mit der Art der Propheten, vom äusseren Hergang unverwirrt, auf die inneren Gesetze der geschichtlichen Ereignisse zu achten. Der Anwendung dieses Bildes auf den nationalen Niedergang und Untergang begegnen wir, in andrer Gestalt, bei Jer. 8, 14. 9, 14 (vgl. 23, 15) Dt. 32, 24. Und den Gedanken, dass Einzelne für die Gesamtheit, oder der König fur sein Volk, oder ein ganzes Volk für das andere, von vergiftendem Einfluss sind, finden wir Dt. 29, 17. Hos. 10, 3. 4. Dt. 32, 32. 33 ausgesprochen.

Die doppelsinnige Verwendung eines Wortes ist in der sonstigen alttestamentlichen Litteratur freilich, soviel ich weiss, nicht anzutreffen, aber demj. wohl zuzutrauen, der gleich darauf das feine Wortspiel mit $\sqrt{ }$ אמן erfunden hat und auch sonst für das Wortspiel (vgl. besonders 5,7.30, I6) eine besondere Vorliebe hat.

Die gesuchte Prägnanz wäre jedenfalls gefunden. Politzig.

Lic. theol. EBERHARD BAUMANN. 